\title{
How Much Are Central Floridians Willing to Pay for Protecting Sea Turtles from Sea
}

\section{Level Rise?}

\author{
Ahmed Hamed ${ }^{1}$, Kaveh Madani ${ }^{2,}{ }^{*}$, Betsy VonHolle ${ }^{3}$, James Wright ${ }^{4}$, J. Walter Milon ${ }^{5}$, Matthew \\ Bossick $^{1}$ \\ ${ }^{1}$ Department of Civil, Environmental and Construction Engineering, University of Central \\ Florida, Orlando, FL 32816, U.S.A. \\ ${ }^{2}$ Centre for Environmental Policy, Imperial College London, London SW7 2AZ, U.K. \\ (" corresponding author, Phone: +44 (20) 7594 9346, Email: k.madani@imperial.ac.uk) \\ ${ }^{3}$ Department of Biology, University of Central Florida, Orlando, FL 32816, U.S.A. \\ ${ }^{4}$ Department of Sociology, University of Central Florida, Orlando, FL 32816, U.S.A. \\ ${ }^{5}$ Department of Economics, University of Central Florida, Orlando, FL 32816, U.S.A.
}




\section{ABSTRACT}

Sea level rise (SLR) is posing a great inundation risk to coastal areas. Some coastal nesting species, including sea turtle species, have experienced diminished habitat from SLR. Contingent Valuation Method (CVM) was used in an effort to assess the economic loss impacts of SLR on sea turtle nesting habitats for Florida coasts; and to elicit values of willingness to pay (WTP) of Central Florida residents to implement certain mitigation strategies, which would protect Florida's east coast sea turtle nesting areas. Using the open-ended and dichotomous choice CVM, we sampled residents of two Florida communities: Cocoa Beach and Oviedo. We estimated the WTP of households from these two cities to protect sea turtle habitat to be between $\$ 42$ and $\$ 57$ per year for five years. Additionally, we attempted to assess the impact of the both the respondents' demographics and their perception towards various situations on their WTP value. Findings include a negative correlation between the age of a respondent and the probability of an individual willing to pay the hypothetical WTP amount. We found that WTP of an individual was not dependent on prior knowledge of the effects of SLR on sea turtle habitat. The greatest indicators of whether or not an individual was willing to pay to protect sea turtle habitat were the respondents' perception regarding the trustworthiness and efficiency of the party which will implement the conservation measures and their confidence in the conservation methods used. Respondents who perceive sea turtles having an effect on their life were also more likely to pay.

\section{Key Words: Sea level rise; sea turtle; ecosystem service valuation; contingent valuation; Florida}

\section{Introduction}

Among the noticeable costs of climate change include that of the sea level rise (SLR) and protection against it (Bosello et al., 2012). Over the past 100 years, the rate of SLR has increased tenfold when compared to the rate over the last two millennia, implying a comparatively recent acceleration in the rate of SLR (Houghton, 2001; Sallenger et al., 2012). It is predicted that the mean sea level will rise 0.6 meters in the next 100 years (Fish et al., 2008). Risk indices classify approximately $15 \%$ of the East Coast of the contiguous United States as being at very high risk of inundation or increased erosion from SLR. The predicted rise in sea levels would threaten many areas of the world with erosion and inundation and poses a great risk to many species that depend on coastal areas to nest and forage for food (Worm et al., 2006). 
Coastal areas are dynamic environments with high economic value and environmental resources. The Florida coastline spans over $2,000 \mathrm{~km}$, and contains diverse ecosystems and landscapes in addition to being habitat for many endangered species. The Florida coastline is especially important for various species of sea turtles. One of the most important nesting areas for loggerhead turtles (Caretta caretta) and green turtles (Chelonia mydas) is the 40.5-km coastline from Melbourne Beach to Wabasso Beach in Florida (Weishampel et al., 2003). SLR, however, has significantly impacted such habitats leading to repercussions to the beach dependent species (Fish et al., 2008).

Ecosystems of intertidal zones will be directly and immediately affected by SLR (Ellison and Stoddart, 1991). In coastal areas with high human activities and development, shoreline structures will prevent landward migration of beaches. Such barriers exacerbate the impact of sea-level rise as beach habitat is lost. Loss of beach habitat will have a negative impact on coastal organisms such as sea turtles (Fish et al., 2008). Sea turtle nesting almost always occurs on low-lying beaches which make them particularly vulnerable to SLR (Yamamoto et al. 2012). Major loss of nesting beaches has hindered efforts to revive the depleted populations of sea turtles. Their survival is greatly threatened by the loss of their habitat. A reduction in habitat area will result in a higher concentration of nesting density, thus increasing density-related issues including increased nest infection (Fish et al., 2008) and crowding, which has the potential for nests to be lost by females nesting on top of existing nests (Canbolat, 2004). Increased egg mortality will result from such occurrences and affect the reproductive success of the green turtle population (Fuentes et al., 2010).

Sea turtles have various ecological roles, including: nutrient cycling, which is crucial for the coastal ecosystem; and maintenance of sea grass beds, coral reefs and beach dunes (Moran and Bjorndal, 2005, Hannan et al. 2007). Losing such services potentially affects the dynamics of near-shore ecosystems (Heithaus et al., 2005). Aside from the obvious ecological services sea turtles provide, due to their charismatic nature, they contribute in generating tourism activities, yielding great economic benefits (Clem and Clevo, 2001). Sea turtles and their habitat have social, ecological, and economical values that cannot be accurately measured using traditional market valuation techniques (Carson and Bergstrom, 2003) such as altruistic, bequest, existence and option value (Brown, 1997).

Valuing ecosystem services provided by sea turtles is essential for assessing the efficiency of alternative ecosystem conservation policies and cost-benefit analysis of various restoration programs (Wilby et al., 2010). However, in order to effectively estimate the value of such services, valuation techniques which incorporate both 
market and non-market values of the ecosystem service are necessary. The ecosystem service provided by sea turtles encompasses a variety of categories. In an effort to analyze the impacts of human action on ecosystems, the Millennium Ecosystem Assessment (2005) identified these ecosystem service categories as: provisioning, regulating, cultural and supporting services. Various studies have been conducted to valuate ecosystem services that fall under these categories (Lewis, 2011; Naber et al., 2008; Fu et al., 2011; Lindsey and Knaap, 1999). The services within these categories are provided directly and indirectly, and make up the total economic value of the ecosystem service (Figure 1).

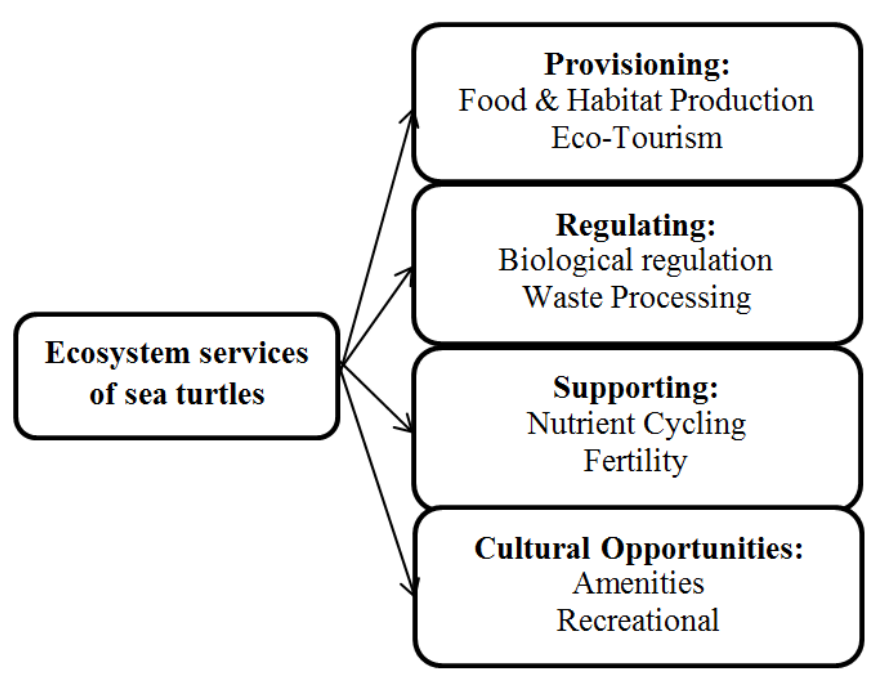

Figure 1 Ecosystem services provided by sea turtles, their activities and their habitat

The value of a commodity falls within the market value category if the service or good can be purchased or sold. But, a pure public good lacks a market because of its non-excludable or non-rival nature (Hanemann, 1994). Non-market values, on the other hand, are different in that they do not have an appraisable market price and cannot be traded directly in markets. Consequently, valuation methods which rely solely on a market value are inapplicable (Bennett and Blamey, 2001). A more accurate estimate would be achieved if other values are considered as part of the total value of the environment, including option and existence values (Brookshire et al., 1983). Furthermore, within the non-market value category, there are use and non-use values (Carson and Bergstrom, 2003) such as bequest, option and existence value. Bequest value is the value an individual is willing to pay to protect some public good for future generations; and option value is the value an individual is willing to pay to protect some public good they are unlikely to use, just to have the option to use it in the future if they pleased. The value an individual is 
willing to pay to maintain the mere existence of some public good or service is described as the existence value. Failure to include the various nonuse values of the ecosystem service under consideration will result in an underestimation of the service benefit; consequently, resources devoted to conservation measures may be under allocated (Whitehead, 1993).

Contingent valuation is a stated preference method which draws upon economic theory and methods of survey research to directly elicit the value of some good or service from the consumer (Mitchell and Carson, 1989). It was first used by Robert Davis in early 1963 by and subsequently by others for various environmental and ecosystem valuation purposes (Desvousges, 1987; Loomis, 2000; Whitehead, 2003; Bandara and Clem 2004, Ojeda et al., 2007). When using the contingent valuation method (CVM), the hypothetical market being valued must not be abstract but rendered in terms of specific items (Hanemann, 1994). Although significant academic research has been dedicated to estimate the economic value of various environmental services (Ready et al., 1995; Loomis 1996, Singh 1997) including sea turtles (Whitehead, 1993), none have sought to estimate the willingess to pay to protect sea turtles from SLR. This paper empirically estimates the willingness to pay of residents from two central Florida cities for measures to protect the sea turtle population. The area of focus for this study is Florida's east coast sea turtle nesting sites. Residents from the cities of Cocoa Beach (a coastal community) and Oviedo (an inland community) were interviewed as representative central Floridian communities and CVM was used in order to empirically measure the total economic value of the ecosystem service provided by sea turtles.

In the next section of this paper we describe CVM. The Results section (section three) presents the WTP values estimated using data obtained from the open-ended and dichotomous choice WTP questions. We then use regression analysis to assess if respondent characteristics, prior knowledge and their views towards conservation efforts, methodology of conservation and ecotourism affect their WTP values. We also discuss the determinants of WTP according to our binomial logit models. This is followed by a discussion of the major limitations that we faced during this research (section four). Section five concludes with presenting the policy implications of our findings.

\section{Materials and Methods}

\subsection{Contingent Valuation Method (CVM)}

Sea turtle habitat is an environmental public good and no market exists that can be used for its valuation. However, a hypothetical market can be created for it and this market can then be evaluated. CVM is the most 
popular method used to evaluate such hypothetical markets. Thus, CVM was used in this study to estimate the total economic value of the service provided by sea turtles of Florida coasts to two central Florida cities. In other words, a survey (See Appendix) was used in order to elicit respondents to indicate their WTP to protect the sea turtle habitat of Florida coasts.

A CVM survey was conducted in two Florida cities, namely Oviedo, an inland city, and Cocoa Beach, a coastal city with sea turtle nesting sites. These cities were chosen because of their differences in proximity to sea turtle nesting sites. Designing a survey is a difficult task because they are vulnerable to errors. Avoiding bias in wording survey questions as well as avoiding a biased sample selection is crucial to the quality of the study. The design and pretest of the survey was conducted in the fall of 2012, with the support of the Survey Research Laboratory at the University of Central Florida (UCF). Respondents were presented with a hypothetical market and were directly asked their willingness to pay for the service or good in the hypothetical market or scenario (Refer to questions 1-3, Appendix).

When using surveys, the scenario should not be abstract and the respondent will must able to evaluate a specific scenario. Mitchell and Carson (1989) suggested that the challenge of a contingent valuation study is to create a scenario which is "sufficiently understandable, plausible and meaningful to respondents so that they can and will give valid and reliable values". For example, in case of Sea turtle habitat against SLR, the survey must aim to clearly present to the respondent the nature of the improvement, the payment vehicle which will be used to fund the improvements, and the party responsible for performing the improvements.

The theory behind CVM follows the theory of welfare economics suggesting that the value of a good or service is the most someone is willing to pay for it (Mitchell and Carson, 1989). The WTP value can be calculated by averaging the open-ended values provided by respondents and by using the Turnbull estimator method (Turnbull, 1976). The Turnbull estimator, used to estimate the mean WTP of respondents, is a maximum likelihood nonparametric estimator (Ahtiainen, 2007). In this study, this estimating method was paired with other techniques used to reduce hypothetical bias. Hypothetical bias arises in contingent valuation studies when the respondents' reported WTP exceeds the actual amount that people would pay (Loomis, 2011). To reduce the hypothetical bias in our study, the survey allowed respondents to indicate how certain they are of their answers. A scale ranging from 1 to 10 was used to recode the respondent's answers. If a respondent answered "yes" to a WTP question but indicated a certainty 
level of 6 or less, their answer was inputted as a "No" in the analysis. Evidence suggests this practice yields a hypothetical WTP value relatively closer to the adjusted cash WTP and thus will reduce hypothetical bias (Park and MacLachlan, 2008; Blumenschein et al 2008; Morrison and Brown, 2009).

\subsection{Survey design}

The survey challenge was to present a clear questionnaire which a logical respondent can read, analyze and answer according to their best judgment. Any description, picture or question in the survey was pretested in order to assure that no item was ambiguous. The survey had a description of the harm faced by sea turtles from SLR. This scenario was discussed in detail, leading to a hypothetical market to be evaluated. This included the market that was to be changed or improved, and the institution that would be responsible for overseeing such changes. Face-to-face interviews were chosen because this allowed the interviewers to remind the respondent to give the value they actually were willing to pay, and not what they thought was the "winning answer".

The Dichotomous Choice (DC) and open-ended techniques were adopted for the price elicitation of our study (Hanemann et al., 1991). These methods are considered to yield a more precise welfare estimate, which is to consider individual preferences (McLeod and Bergland, 1999), and are highly efficient when compared to the single bound technique (Hanemann et al., 1991). Additionally, their simplicity of use for data collection along with the relative easiness for respondents reduce some of the concerns associated with bias in the WTP results obtained using CVM. The DC technique has also been found to be useful when analyzing data with a small sample size. Kanninen (1995) calculated the bias of the DC and the single model estimates in a sample size of 100 observations and found that DC techniques have less bias.

\subsection{CVM scenario}

Respondents were given information and shown diagrams depicting the potential loss of sea turtle nesting habitat due to both SLR, and increased coastal development. This was followed by presentation of the hypothetical scenario which identified the specific market to be valued, the improvements that would be made to this market, the payment vehicle and the method in which such improvements would be financed.

Following this passage, a set of questions were presented. Not all the questions were subject to being answered based on the DC technique used for the survey. The respondents were presented with a value and if they indicated they were willing to pay this amount, they were then asked about an amount greater than the first one; however, if 
they indicated they were not willing to pay the first amount, the second amount would be lower. Three different versions of the survey existed, and respondents received one of the surveys randomly with bid values ranging from $\$ 10$ to $\$ 75$.

Following the DC style questions, an open-ended question was made available. The open-ended option allowed respondents that answered "no" to a WTP of $\$ 10$ or "yes" to a WTP of $\$ 75$ to specify what their maximum WTP is. This style was expected to allow for greater efficiency and higher accuracy in indicating the WTP value (Yu and Abler, 2010). Additionally, a question was available to allow respondents to indicate their certainty in their answers on a scale of $1-10$.

Lastly, a set of eight statements was presented, and the respondents gave their opinions by assigning a value between 1 and 5 for each statement ( $1=$ strongly disagree, $5=$ strongly agree $)$.

- S1- Prior to this survey I was aware of the effects of SLR on sea turtles.

- S2- Sea turtle nesting habitat on Florida's coast should be protected.

- S3- The health of the sea turtle population will affect the ecosystem.

- S4- I enjoy seeing/would enjoy seeing sea turtles in their habitat.

- $\quad$ S5- The health of sea turtle population will have an effect on my life.

- S6- Sea turtle population will affect tourism in coastal cities.

- $\quad$ S7- Limiting coastal development is a good step to conserve sea turtle habitat.

- S8- Money collected for sea turtle conservation measures will be honestly and efficiently used.

The eight statements were used to gather information regarding the respondents' awareness of SLR, their opinion on mitigation strategies success, their perception regarding the importance of the ecosystem on their daily lives, the linkage between the ecosystem and local economy and their level of trust in the use of funding for conservation efforts. Using these questions allowed us analyze the correlations between their results with their indicated WTP values. The resulting information is expected to provide valuable insight for policy makers trying to understand the perception of stakeholders regarding various conservation efforts in Florida.

\subsection{Sample selection}


In choosing the survey population sample we specified the population of interest, the sample frame and the method in which the survey would be conducted. Due to our interest in finding the WTP of coastal city residence and that of inland city residence, we chose to conduct face-to-face interviews with respondents from the coastal city of Cocoa Beach and the inland city of Oviedo. We then used the 2010 U.S. Census Bureau data for those cities to randomly generate a list of city blocks, which were used to conduct the interviews. Once the blocks were designated, interviewers attempted to interview all residents of that block, provided that they were available and willing to participate in an interview when the interviewers were present in the neighborhood. A total of 72 respondents were interviewed in Cocoa Beach, and 71 respondents were interviewed in Oviedo. Such a sample size was believed to be adequate statistically (Loomis et al., 2000).

A comparison of some demographics between the surveyed group and the two communities is presented below (Table 1). This table shows that the sample group was older and had a higher number of female respondents. The sample had a slightly lower reported median household income, and was nearly identical to the communities' high school completion rate.

Table 1 Demographics of the sample surveyed compared to that of the two cities

\begin{tabular}{lcc}
\hline \multicolumn{1}{c}{ Variable } & $\begin{array}{c}\text { Sample } \\
\text { Average }\end{array}$ & $\begin{array}{c}\text { Cities } \\
\text { Average }\end{array}$ \\
\hline Age & 48.00 & 36.9 \\
$\begin{array}{l}\text { Completed High School } \\
(\%)\end{array}$ & 90.20 & 90.9 \\
$\begin{array}{l}\text { Median Household } \\
\text { Income (1000's \$/year) }\end{array}$ & 57.30 & 64.4 \\
Female/Male Ratio & 1.2 & 1.0 \\
\hline
\end{tabular}

\section{$3 \quad$ Results}

The open-ended values were averaged to estimate the WTP, and were further evaluated in a regression analysis to evaluate possible correlations between respondent characteristics and their WTP. Turnbull estimator was used as the tool to estimate the WTP from the dichotomous choice data.

The open-ended approach to elicit WTP values provided more freedom to respondents wanting to give a value that might not be found within the pre-determined values presented in a DC approach. The mean WTP using the open-ended values are presented in Table 2. This is compared to the mean values of the first and second values 
respondents encountered from the DC questionnaire. It was found that the average WTP during the open-ended questionnaire exceeded the mean of the first value offered and that of the second indicating that the two values presented to the respondents did not capture the maximum willingness to pay of many of the responders.

Table 2 Estimated WTP from open-ended data

\begin{tabular}{lccc}
\hline \multicolumn{1}{c}{ Descriptive Statistics } & $\begin{array}{c}\text { Open-ended } \\
\text { WTP (\$) }\end{array}$ & $\begin{array}{c}\text { First Value } \\
\text { Presented (\$) }\end{array}$ & $\begin{array}{c}\text { Second Value } \\
\text { Presented (\$) }\end{array}$ \\
\hline Minimum & 0.00 & 20.00 & 10.00 \\
Mean & 57.10 & 32.07 & 50.64 \\
Median & 50.00 & 30.00 & 55.00 \\
Maximum & 500.00 & 40.00 & 75.00 \\
Standard deviation & 54.39 & 7.51 & 20.34 \\
\hline
\end{tabular}

A regression analysis was used to compute any significant correlations between the WTP values, given by the respondents, and their demographics. We were also interested in finding the effects of the dichotomous choice values presented to the respondents on their maximum WTP (Table 3). It was found that the second value presented to the respondents had a statistically significant correlation to the maximum WTP value. This indicates the maximum WTP value was influenced by the two values initially given in the questionnaire. Additionally, the age of the respondents was found to correlate with the WTP value in a negative way. That is, as the age of the respondents increased the WTP value decreased as indicated by the coefficient of -7.09 . This decrease could be an indication of higher responsibility in assessing the question among older responders. It can also be argued that younger generations are more willing to make greater concessions for environmental conservation. Additionally, an analysis was conducted between the WTP values indicated by respondents and their responses to the 8 statements provided in the questionnaire (Appendix, question7). The respondents were to indicate their level of agreement to the listed statements. It was found that statements S5, S7 and S8 had significant positive correlations with the indicated maximum WTP (Table 3).

Table 3 Correlations between the open-ended WTP values and demographics of the respondents

\begin{tabular}{lcccc} 
& Coefficients & Standard Error & t Stat & P-value \\
\hline \hline Intercept & 69.26 & 34.75 & 1.99 & 0.04 \\
First Value Presented & -0.84 & 0.61 & -1.37 & 0.17 \\
$\begin{array}{l}\text { Second Value } \\
\text { Presented }\end{array}$ & 1.29 & 0.22 & 5.78 & $0.00^{* * *}$
\end{tabular}




$\begin{array}{lcccc}\text { Age of Respondent } & -7.09 & 3.84 & -1.84 & 0.06^{*} \\ \text { Gender } & 2.05 & 8.46 & 0.24 & 0.8 \\ \text { Education } & -5.37 & 5.72 & -0.93 & 0.35 \\ \text { Household Income } & 1.97 & 3.46 & 0.56 & 0.57 \\ \text { Number of Years } & & & \\ \text { Residing in Florida } & -5.7 & 4.77 & -1.19 & 0.23 \\ \text { Intercept } & & & & \\ \text { S1 } & -84.364 & 39.279 & -2.148 & 0.034 \\ \text { S2 } & -0.091 & 3.577 & -0.025 & 0.98 \\ \text { S3 } & 15.458 & 10.763 & 1.436 & 0.153 \\ \text { S4 } & 10.99 & 8.32 & 1.321 & 0.189 \\ \text { S5 } & -8.081 & 9.696 & -0.833 & 0.406 \\ \text { S6 } & 8.953 & 5.042 & 1.776 & 0.078^{*} \\ \text { S7 } & 5.637 & 6.415 & 0.879 & 0.381 \\ \text { S8 } & 15.307 & 7.561 & 2.024 & 0.045^{*} \\ & 16.405 & 5.376 & 3.051 & 0.003^{* *}\end{array}$

Values marked with an asterisks $(*)$ have a statistically significant correlation. Codes of significance: $*=0.01 * *=0.001 * * *=0$

The dichotomous choice contingent valuation method (DC-CVM) offers a limited insight into the true WTP of an individual. If a responder answers "Yes" to a WTP value, this indicates that the responder is willing to pay that value or more. If the responder then answers "No" to the higher value provided, it is evident that the WTP is between that first and second value (Haab and McConnell, 2002). In our analysis, the WTP value was calculated using the Turnbull estimator method (Turnbull, 1976). Using the upper and lower bounds, the Turnbull estimator constructs an interval estimate for the WTP based on the values given by the respondents in the survey (Ahtiainen 2007). As expected, the percentage of respondents voting "Yes" for the proposed referendum question decreased as the dollar amount increased.

The Turnbull estimator uses the "yes" or "no" responses provided by the respondents to construct WTP intervals. The respondent is first asked if they are willing to pay a value, if they answer yes to that value. A second question asks if they are willing to pay a higher value. If they say no, however, they are asked if they are willing to pay a value lower than the first value they encountered. These choices were combined to obtain estimates for the frequency of responses of the different WTP intervals (Carson et al., 2004). The bids randomly distributed between the respondents were $\$ 10, \$ 15, \$ 20, \$ 25, \$ 30, \$ 40, \$ 45, \$ 55$, and $\$ 75$. Table 4 below presents the nine intervals defined by the bid amounts.

Table 4 Responses to bid intervals 


\begin{tabular}{ccccc}
\hline $\begin{array}{c}\text { Lower Bound } \\
(\mathbf{\$})\end{array}$ & $\begin{array}{c}\text { Upper bound } \\
\text { (\$) }\end{array}$ & $\begin{array}{c}\text { Number of } \\
\text { Yes }\end{array}$ & Probability of Yes & $\begin{array}{c}\text { Change in } \\
\text { Density }\end{array}$ \\
\hline $\mathbf{0}$ & 10 & 121 & 0.86 & 0.14 \\
$\mathbf{1 0}$ & 15 & 120 & 0.86 & 0.01 \\
$\mathbf{1 5}$ & 20 & 118 & 0.84 & 0.01 \\
$\mathbf{2 0}$ & 25 & 113 & 0.81 & 0.04 \\
$\mathbf{2 5}$ & 30 & 104 & 0.74 & 0.06 \\
$\mathbf{3 0}$ & 40 & 84 & 0.60 & 0.14 \\
$\mathbf{4 0}$ & 45 & 72 & 0.51 & 0.09 \\
$\mathbf{4 5}$ & 55 & 56 & 0.40 & 0.11 \\
$\mathbf{5 5}$ & 75 & 38 & 0.27 & 0.13 \\
$\mathbf{7 5}$ & $\infty$ & 0 & 0.00 & 0.27 \\
\hline Turnbull Estimate & $\$ 42.89$ & & \\
\hline
\end{tabular}

To calculate the Turnbull WTP value, the sum product was calculated between the lower bound values and the change in density as follows:

$$
\begin{gathered}
(0 a s f o)+(10 s f o l)+(15 s f o l)+(20 s f o l)+(25 s f o l)+(30 s f o l)+(40 s f o l)+(45 s .11)+(55 s .11) \\
+(75 s .11)=\$ 42.89
\end{gathered}
$$

The estimated WTP using this method was $\$ 42.89$. The median $\left(50^{\text {th }}\right.$ percentile $)$ value of WTP falls in the $\$ 45$ to $\$ 55$ range (Table 5). The first two columns of Table 5, present the lower and upper bound values of the intervals. The third column presents how many respondents had said yes to the value presented to them of the 141 that participated in the survey. An estimated $86 \%$ of all respondents agreed to pay a value between $\$ 0$ and $\$ 10$.

To estimate the economic influence of the respondents' opinions on their WTP, we compared the estimated WTP of respondents who selected "agree/strongly agree" for the S1-S8 statements versus the WTP of those who selected "disagree/strongly disagree". Table 5 presents the estimated WTP of respondents that agreed or strongly agreed to a specific statement (column 2) compared to the WTP of respondents that disagreed or strongly disagreed to the statements (column 4). The last column of this table presents the percentage increase between the WTP of respondents who agree versus those who disagree.

The overwhelming majority of respondents (94\%) agreed that action must be taken in order to protect sea turtle nesting habitats of Florida coasts (S2) as can be seen in Table 5. These respondents were willing to pay on average $\$ 21.76$ per year for five years. Those who agreed or strongly agreed with the statement "limiting coastal development is a good step to conserve sea turtle habitat" (S7) were willing to pay on average $\$ 27.07$ per year for 
five years more than those that disagreed with S7. This was found to be the greatest difference in the WTP between individuals who agreed or disagreed to a statement.

Table 5 Hypothetical WTP (\$) by category of opinions

\begin{tabular}{lcccc}
\hline & $\begin{array}{c}\text { WTP value of } \\
\text { respondents indicating } \\
\text { "Agree/Strongly Agree" }\end{array}$ & $\begin{array}{c}\text { Percentage } \\
\text { agreed }\end{array}$ & $\begin{array}{c}\text { WTP value of respondents } \\
\text { indicating } \\
\text { "Disagree/Strongly } \\
\text { Disagree" }\end{array}$ & $\begin{array}{c}\text { Percentage } \\
\text { increase }\end{array}$ \\
\hline S1 & 31.56 & $62 \%$ & 28.41 & $11 \%$ \\
S2 & 29.26 & $94 \%$ & 7.50 & $290 \%$ \\
S3 & 32.34 & $81 \%$ & 7.50 & $331 \%$ \\
S4 & 29.26 & $91 \%$ & 7.50 & $290 \%$ \\
S5 & 35.20 & $52 \%$ & 12.07 & $192 \%$ \\
S6 & 33.17 & $67 \%$ & 7.50 & $342 \%$ \\
S7 & 30.82 & $88 \%$ & 3.75 & $722 \%$ \\
S8 & 29.73 & $67 \%$ & 14.38 & $107 \%$ \\
\hline
\end{tabular}

When comparing the hypothetical WTP values of respondents that agreed or disagreed to the statement that the health of the sea turtle population will have an effect on their lives (S5), we found a typical difference of $\$ 23.13$ per year. What must be noted here is that this yielded the highest hypothetical WTP value $(\$ 35.20)$, which is an indication that individuals that perceive an improvement to their lives as the state of the sea turtle population improves give a higher value to sea turtles. Additionally, it was found the respondents that were familiar with ecotourism (S6) were willing to pay $\$ 25.67$ more than those who were not. These findings provide us with insight into likely aspect of sea turtle ecosystems which is highly valued among people. And thus, the difficult task of raising conservation awareness efforts can be appropriately guided.

Respondents agreeing to the statement "The health of the sea turtle population will affect the ecosystem" (S3) were willing to pay $\$ 24.84$ per year for five years more than those who disagreed (Figure 2). This difference was \$201.76 when the statement was "I enjoy seeing/would enjoy seeing sea turtles in their habitat" (S4. This is an indication of the non-use value that is placed on the commodity. 


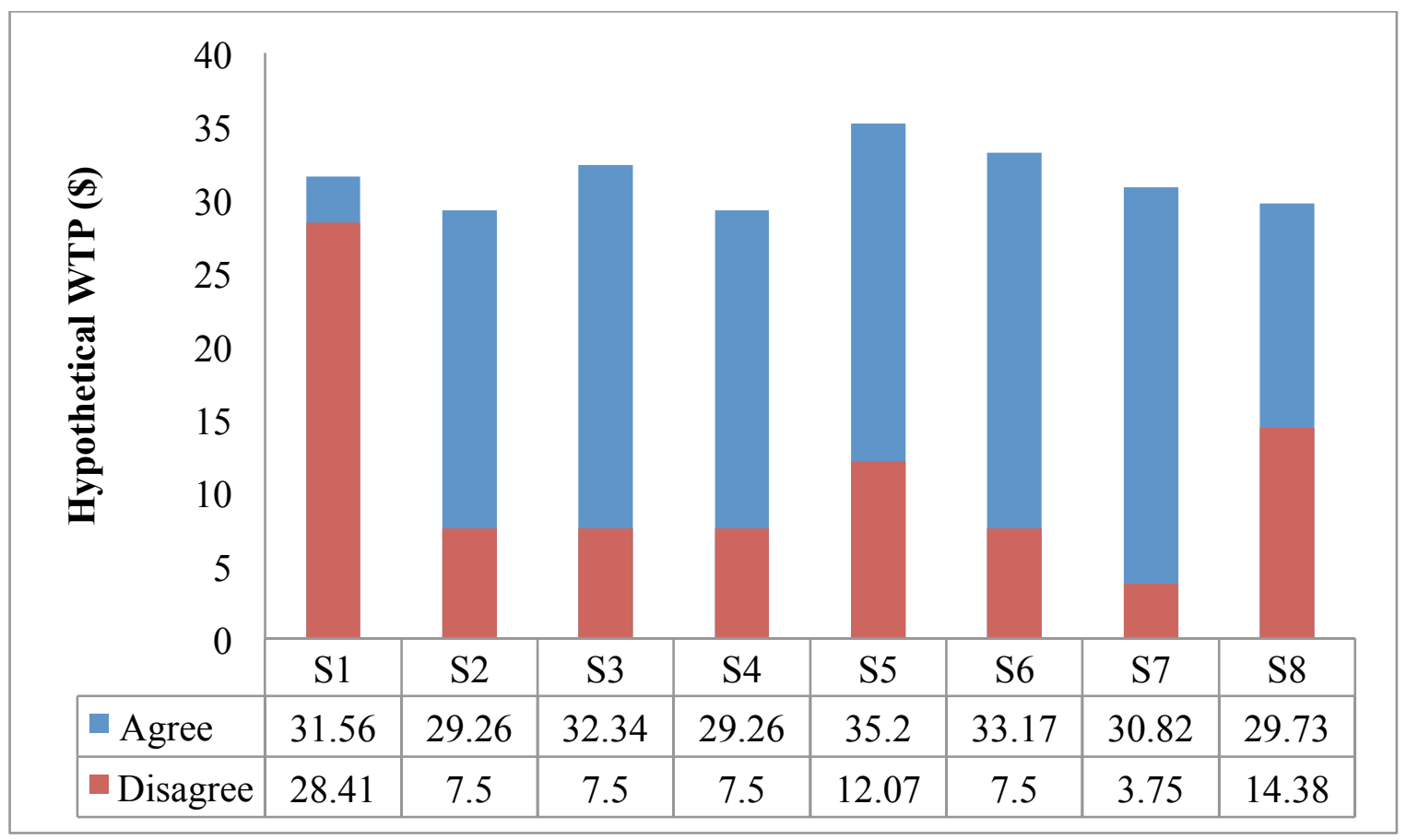

Figure 2 The influence of opinion on WTP

\section{Limitations}

The CVM has greatly improved over the years with more researchers applying this method to a broader range of valuation needs. However, it is still relatively controversial, and some question whether it accurately measures the WTP for maintaining the environmental quality of the public goods. This concern mainly stems from the understanding that people are unfamiliar with placing dollar values on environmental or public goods and services. For a greater efficiency in bid collection the dichotomous choice method was employed in this study. This, however, can introduce a source of bias as it provides some kind of expectation for the respondent (Karl, 1985).

Results show a strong correlation between individuals that agreed with statements S5, S7 and S8 of the survey, and the probability to pay. Such correlation indicates that the payment method and the method of the improvement affected the responder's answer. This expresses that answers to the WTP question may be biased because the respondents express their feelings about the scenario or the mitigation method rather than the value for the good. Additionally, the results of this survey might have been affected by anchoring. This means that respondents might have overexpressed their willingness to pay with the provided image of a bitter future of sea turtles under business as usual, i.e. without the provided information. Some of these responses were protest answers; this was obvious in a few surveys when respondents indicated they would not be willing to pay anything as soon as they learned the 
payment vehicle is an increased tax. Other payment vehicles considered include donations. However, the decision to use a tax increase as the payment vehicle was made to avoid any respondents giving a "free rider" answer, meaning they give a value that they do not believe they will pay because they have a choice. Further research is warranted in designing contingent valuation surveys to avoid responses' dependent on the payment vehicle and the method of improvement. Other limitations included reaching a larger sample size in a higher number of areas. For example, the population of the two cities in our study was 44,573 (2010 Census). Therefore, using the $95 \%$ confidence intervals in a sample of 142 drawn from this population are plus or minus 8.21 percentage points. Because interviews were face to face, our ability to send out mass requests for survey completion was hindered. An interviewing method to reach a larger sample would be desirable; however, this type of survey completion requests was avoided to reduce noise and bias responses.

\section{Conclusions}

This paper reports the results of our research on assessing the estimated amount Floridians are willing to pay for the protection of sea turtles from SLR. CVM was applied to estimate the willingness to pay (WTP) of Florida residents to protect this natural commodity. Residents from two Florida cities, namely Cocoa Beach and Oviedo, participated in a survey interview and were asked to indicate their WTP to protect sea turtle nesting habitat. In development of the survey and collection of the data, decisions were made to reduce the presence bias responses. The extent of effort that went into reducing bias was to assure we obtain an estimated WTP value close to the actual value respondents would be willing to pay. The survey was designed with the assistance of UCF's Survey Research Laboratory and introduced the respondents to the phenomena of SLR and its effects on coastal areas. Additionally, the survey discussed the mitigation strategies considered to protect sea turtle nesting, the agency which will administer such mitigation projects, and the vehicle of fund collection. The survey also allowed respondents to indicate their views on eight statements by choosing whether or not they agree with the statement. Their responses were then used by a regression analysis model to investigate correlations between individuals' views on the statements and their WTP. This model was also used to draw correlations between respondents' demographics to their WTP. Notably, we found a negative correlation between age and WTP.

An open-ended survey and the Turnbull method were used in order to estimate the hypothetical WTP of Floridian residents. Our findings estimate the potential aggregate WTP value of residents from these two cities to be 
between $\$ 9.5$ million and $\$ 12.5$ million dollars over a five-year period to help protect sea turtle nesting habitat from the impacts of SLR.

We found that the difference between the WTP of the two surveyed cities was negligible. Greater differences in WTP, however, were found between those who agreed versus those who disagreed to the eight statements. Upon indicating their WTP value, respondents answered "agree" or "disagree" to a list of statements. The estimated WTP value was higher when respondents agreed to statements such as "The health of the sea turtle population will affect the ecosystem", "Sea turtle population will affect tourism in coastal cities", and "Limiting coastal development is a good step to conserve sea turtle habitat". We also found that prior knowledge of the effects of SLR on sea turtle nesting habitat did not increase an individual's WTP. The WTP to protect sea turtle nesting habitat was approximately $331 \%$ greater when individuals indicated they agreed with statement S3 ("The health of the sea turtle population will affect the ecosystem"). These findings provide valuable insights to individuals concerned with establishing methods to raise public interest and funds for conservation projects.

Our findings suggest that the top indicators of an individual's WTP include their trust in the proposed mitigation method, as well as their understanding of eco-tourism and the ecosystem. The latter suggests that educating the public on the interconnectedness of sea turtle population and the ecosystem health is likely to increase the WTP. In our findings, the aggregate WTP values provide decision makers with estimates on how much Floridians value Sea turtles. Also, our correlation analysis provides insight to conservationists on which aspect of sea turtle ecosystems is highly valued among people and which awareness strategy is likely to create the greatest contribution to protection of the species. 


\section{Acknowledgements}

The authors would like to thank Rachel Morgan at the UCF's Survey Research Laboratory for her helpful suggestions in the designing of the survey and thank the members of the Hydro-Environmental and Energy Systems (HEESA) research group for their constructive feedback during this research. The authors also acknowledge the major efforts of Annette Spivy, David Rothkopf, Robert Papson, Ouissam Mouri, Kinza Shuja, Juan Gonzalez, Landon Harris, Steven Carrion at the University of Central Florida and their major assistance in the interviewing process. Funding from the US Fish and Wildife Service (F11AC00460) to advance the Conservation Blueprint of the South Atlantic Landscape Conservation Cooperative is also appreciated. 


\section{References}

Ahtiainen H (2007) Willingness to Pay for Improvements in the Oil Spill Response Capacity in the Gulf of Finland-an Application of the Contingent Valuation Method. Master's thesis, University of Helsinki

Bandara R, Clem T (2004) The Net Benefit of Saving the Asian Elephant: A Policy and Contingent Valuation Study. Ecological Economics 48, no. 1: 93-107. doi: 10.1016/j.ecolecon.2003.01.001

Bennett J, Russell B (2001) The Choice Modelling Approach to Environmental Valuation. Edward Elgar Publishing, UK, pp 37-72

Blumenschein K, Glenn C.B, Magnus J, Nancy H, Patricia F (2008) Eliciting Willingness to Pay Without Bias: Evidence from a Field Experiment*. The Economic Journal 118, no. 525: 114-137. doi: 10.1111/j.1468-0297.2007.02106.x

Bosello F, Robert J.N, Julie R, Roberto R, Richard SJ. (2012) Economic impacts of climate change in Europe: sea-level rise. Climatic Change 112, no. 1: 63-81. doi: 10.1007/s10584-011-0340-1

Brookshire D.S, Larry S. E, Alan R (1983) Estimating option prices and existence values for wildlife resources. Land Economics 59, no. 1: 1-15. doi: 10.2307/3145871

Carson R, Mitchell R (1989) Using surveys to value public goods: The contingent valuation method. Resources for the Future, Washington DC

Davis R (1963) Recreation Planning as an Economic Problem. Natural Resources Journal 3, no. 2: $239-244$

Ellison J, Stoddart D (1991) Mangrove Ecosystem Collapse During Predicted Sea-Level Rise: Holocene Analogues and Implications. Journal of Coastal Research 7: 151-165

Fish R, Cote M et al (2008) Construction Setback Regulations and Sea-Level Rise: Mitigating Sea Turtle Nesting Beach Loss. Ocean \& Coastal Management 51, no. 4: 330-341. doi:10.1016/j.ocecoaman.2007.09.002

$\mathrm{Fu}$, B. J., et al. (2011) Double counting in ecosystem services valuation: causes and countermeasures. Ecological research 26.1: 1-14.doi 10.1007/s11284-010-0766-3

Fuentes B, Limpus CJ et al (2010) Potential Impacts of Projected Sea-Level Rise on Sea Turtle Rookeries. Aquatic conservation: marine and freshwater ecosystems 20, no. 2: 132-139. doi: $10.1002 /$ aqc. 1088

Haab T, McConnell K (2002) Valuing Environmental And Natural Resources: The Econometrics of Non-Market Valuation. Edward Elgar Publishing, UK.

Hanemann M (1994) Valuing the Environment through Contingent Valuation. Journal of Economic Perspectives 8 no. 4: 19-43. doi: 10.1257/jep.8.4.19.

Hanemann M, Loomis J, Kanninen B (1991) Statistical Efficiency of Double-Bounded Dichotomous Choice Contingent Valuation. American journal of agricultural economics 73, no. 4: 1255-1263. doi: 10.2307/1242453 
Hannan L, Roth J et al (2007) Dune Vegetation Fertilization by Nesting Sea Turtles. Ecology 88, no. 4: $1053-1058$

Heithaus M, Frid A et al (2005) Biology of Sea Turtles Under Risk From Tiger Sharks at a Foraging Ground. Marine Ecology Progress Series 288: 285-294. doi:10.3354/meps 288285

Kanninen B (1995) Bias in Discrete Response Contingent Valuation. Journal of environmental economics and management 28, no. 1: 114-125. DOI: 10.1006/jeem.1995.1008

Lewis, S. EF. (2011) Valuing an ecotourism resource: a case study of the Boulders Beach African penguin colony.OpenUCT. https://open.uct.ac.za/handle/11427/10787. Accessed 23 February 2015

Lindsey, G., Knaap, G. (1999) Willingness to pay for urban greenway projects. Journal of the American Planning Association 65.3: 297-313.doi:10.1080/01944369908976059

Loomis J (2011) What's To Know About Hypothetical Bias In Stated Preference Valuation Studies? Journal of Economic Surveys 25, no. 2: 363-370. doi:10.1111/j.14676419.2010.00675.x

Loomis J, Kent P et al (2000) Measuring the Total Economic Value of Restoring Ecosystem Services in an Impaired River Basin: Results from a Contingent Valuation Survey." Ecological economics 33, no. 1: 103-117. DOI: 10.1016/s0921-8009(99)00131-7

Loomis J, White D (1996) Economic Benefits of Rare and Endangered Species: Summary And Meta-Analysis. Ecological Economics 18, no. 3: 197-206. doi:10.1016/09218009(96)00029-8

McLeod D, Bergland O (1999) Willingness-To-Pay Estimates Using the Double-Bounded Dichotomous-Choice Contingent Valuation Format: A Test for Validity and Precision in a Bayesian Framework. Land Economics : 115-125

Millennium Ecosystem Assessment (2005). Ecosystems and Human Well-being: Synthesis, Island Press, Washington, DC.

Milon, W. J . (1989) "Contingent valuation experiments for strategic behavior." Journal of Environmental Economics and Management 17, no. 3: 293-308.

Mitchell, R. C., Carson R. T. (2013) Using surveys to value public goods: the contingent valuation method. Routledge.

Moran, K. L., Bjorndal K. A. (2005) "Simulated green turtle grazing affects structure and productivity of seagrass pastures." Marine Ecology Progress Series 305: 235-247.

Morrison, M., Brown, T. C. (2009) "Testing the effectiveness of certainty scales, cheap talk, and dissonance-minimization in reducing hypothetical bias in contingent valuation studies." Environmental and Resource Economics 44, no. 3: 307-326.

Naber, H., Lange, G. M., Hatziolos, M. (2008) Valuation of marine ecosystem services: a gap analysis. World Bank and UNEP-World Monitoring Conservation Center (UNEPWCMC). 
Park, J. H., MacLachlan, D. L. (2008) "Estimating willingness to pay with exaggeration biascorrected contingent valuation method." Marketing Science 27, no. 4: 691-698.

Ready, R. C., Whitehead, J. C., Blomquist, G. C. (1995) "Contingent valuation when respondents are ambivalent." Journal of Environmental Economics and Management 29, no. 2: 181-196.

Sallenger, A. H., Doran, K.S., Howd, P.A. (2012) "Hotspot of accelerated sea-level rise on the Atlantic coast of North America." Nature Climate Change 2, no. 12: 884-888.

Turnbull, B. W. (1976) "The empirical distribution function with arbitrarily grouped, censored and truncated data." Journal of the Royal Statistical Society. Series B (Methodological): 290-295.

Weishampel, J. F., Bagley, D.A., Ehrhart, L. M., Rodenbeck, B. L. (2003) "Spatiotemporal patterns of annual sea turtle nesting behaviors along an East Central Florida beach." Biological Conservation 110, no. 2 : 295-303.

Whitehead, J. C. (1993) "Total economic values for coastal and marine wildlife: specification, validity and valuation issues." Marine Resource Economics 8, no. 2, 119-132.

Wilby, R. L., Orr, H., Watts, G., Battarbee, R. W., Berry, P. M., Chadd, R., Dugdale S. J., et al. (2010) "Evidence needed to manage freshwater ecosystems in a changing climate: turning adaptation principles into practice." Science of the Total Environment 408, no. 19: 4150-4164.

Worm, B., Barbier, E. B., Beaumont, N., Duffy, E. J., Folke, C., Halpern, B. S., Jackson J. BC., et al. (2006) "Impacts of biodiversity loss on ocean ecosystem services." science 314, no. $5800: 787-790$.

Yamamoto, K. H., Powell, R. L., Anderson, S., Sutton, P. C. (2012) "Using LiDAR to quantify topographic and bathymetric details for sea turtle nesting beaches in Florida." Remote Sensing of Environment 125: 125-133.

Yu, X., Abler D. (2010) "Incorporating zero and missing responses into CVM with open-ended bidding: willingness to pay for blue skies in Beijing." Environment and Development Economics 15, no. 05: 535-556. 
APPENDIX: The following is one version of the three surveys which was provided to the respondents. Other versions varied only in the price range in the dichotomous choice values.

\section{UCF RESEARCH SURVEY}

With the funding received by the U.S Fish and Wildlife Service, the University of Central Florida research group, HEESA, is studying the socioeconomic impacts of sea level rise on sea turtles in the state of Florida. Your participation in this research survey is requested.

This survey which takes about ten minutes to complete will be used in part to evaluate the ecosystem services provided by sea turtles. This survey will provide valuable data for the research. Participation in this survey is voluntary, and respondents will not receive any direct benefit. The interviewers are students who have volunteered to conduct these interviews. You must be at least 18 years of age to participate in the survey.

If you have any questions about the study, please contact XXXX, the principal investigator, at 407-823-XXXX. Thank you. 
Climate change has led to a significant increase to the mean sea level in the past few decades. One of the impacts of sea level rise includes loss of coastal areas. Reduction in coastal areas translates to a decrease in the nesting habitat of certain species. This could be detrimental to the survivability of coastal nesting species such as sea turtles. (See Figures $1 a$ and $1 b$ below)

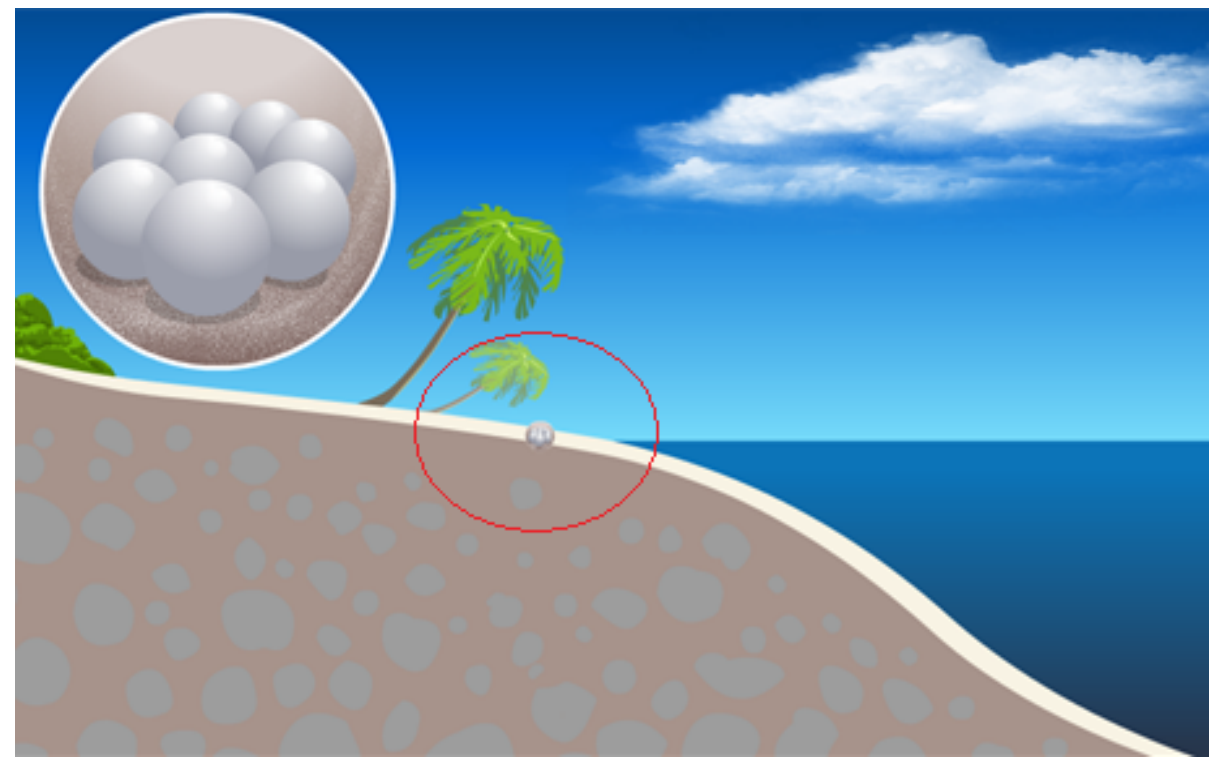

(Figure 1a: A sea turtle nest prior to sea level rise)

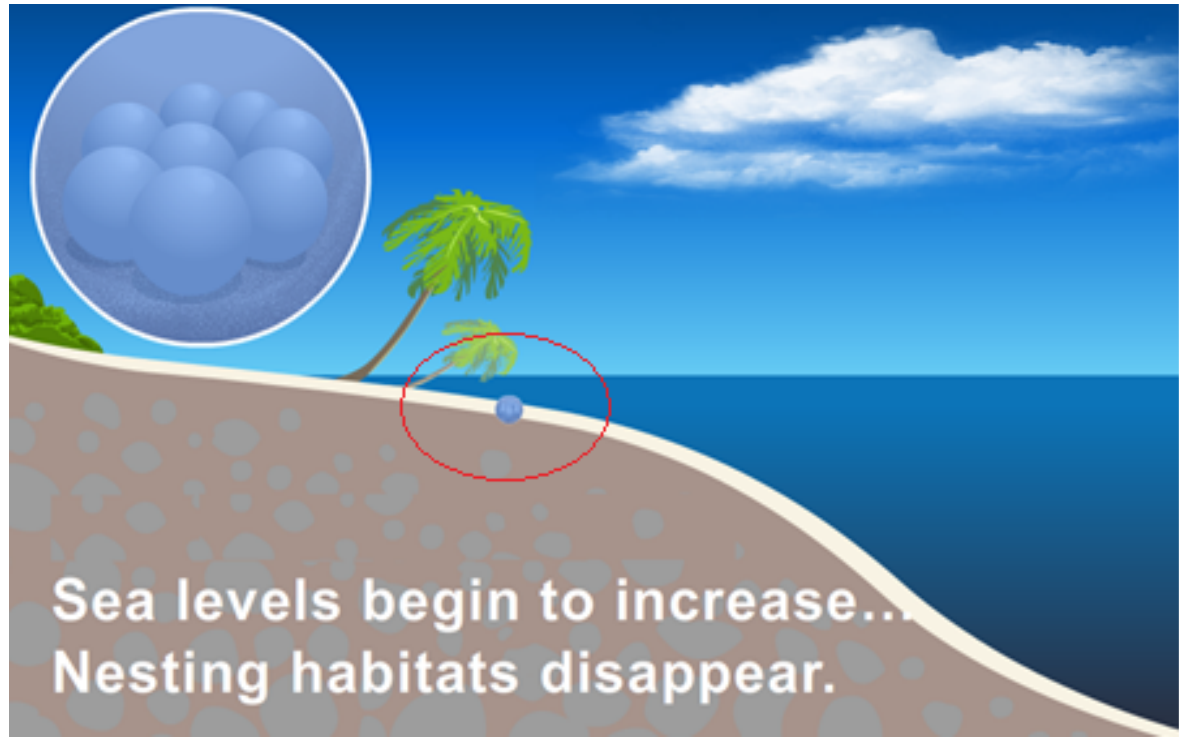

(Figure 1b: A sea turtle nest after sea level rise)

Sea turtles have existed and benefited the earth for over 100 million years. They maintain the habitats of other species such as coral reefs, and sea grass beds; additionally they contribute to the process of nutrients cycling, and balancing the food web. In the past few decades their numbers have drastically declined and are now considered endangered. (See Figure $2 a$ and $2 b$ ) 


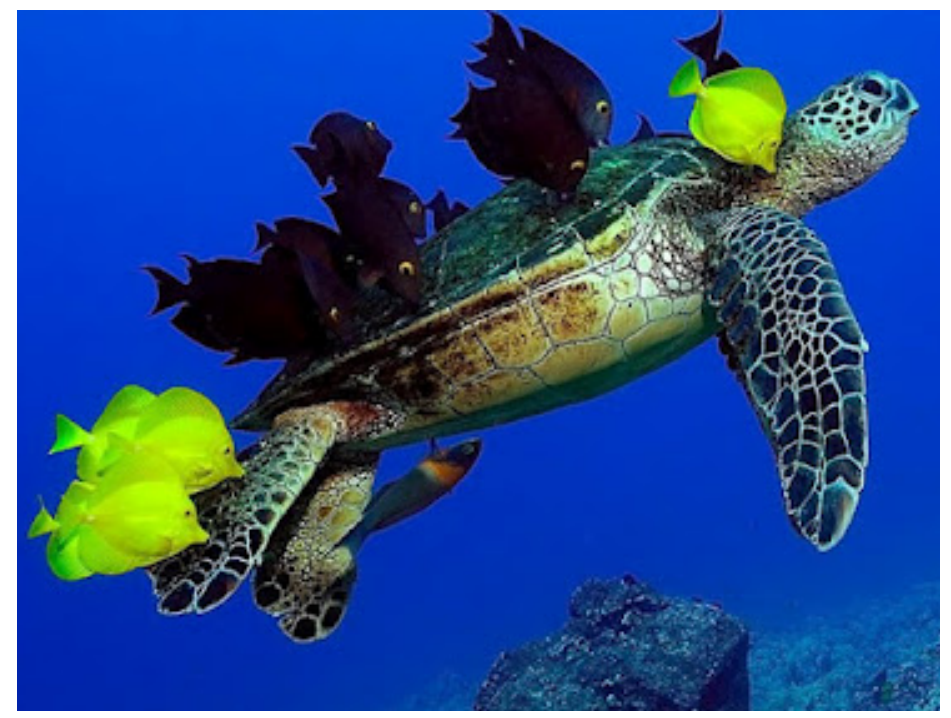

(Figure 2a: 90\% of all loggerhead nesting in the United States occur in Florida)

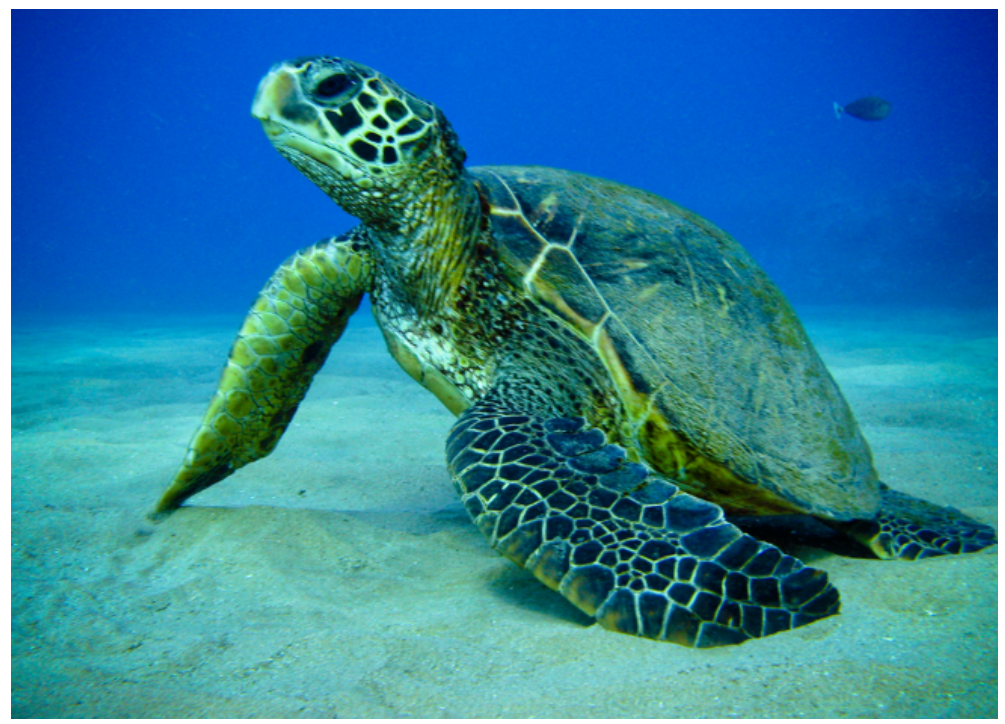

(Figure 2b: Green turtles are the second most common sea turtle on Florida coasts)

The level at which sea level rise will impact the sea turtle habitat is largely dependent on the land-use behind the beach and whether the inland retreat of habitat is restricted. Under natural conditions beaches will shift landward in response to a rise in the sea level. But in areas which have high human modification and development, sea level rise can eradicate coastal habitats. (See Figures $3 a$ and $3 b$ ) 


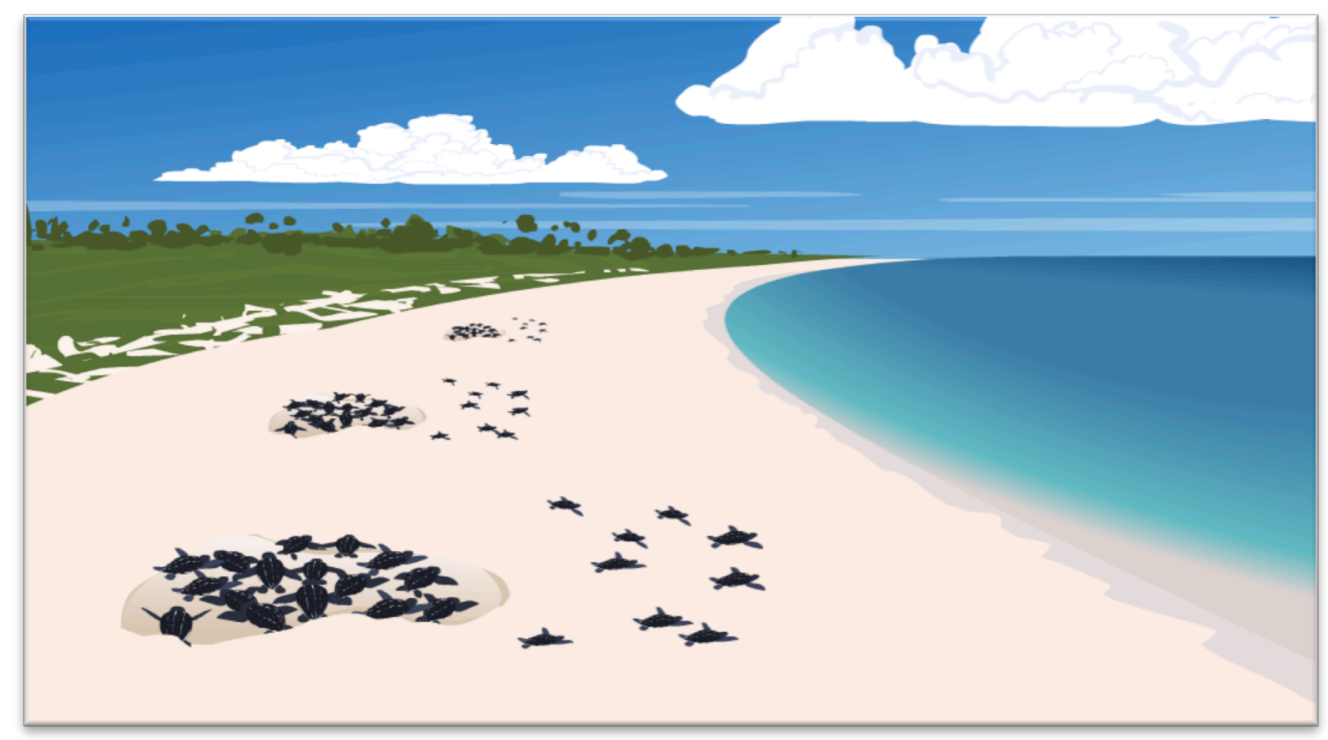

(Figure 3a: A depiction of an unrestricted nesting habitat)

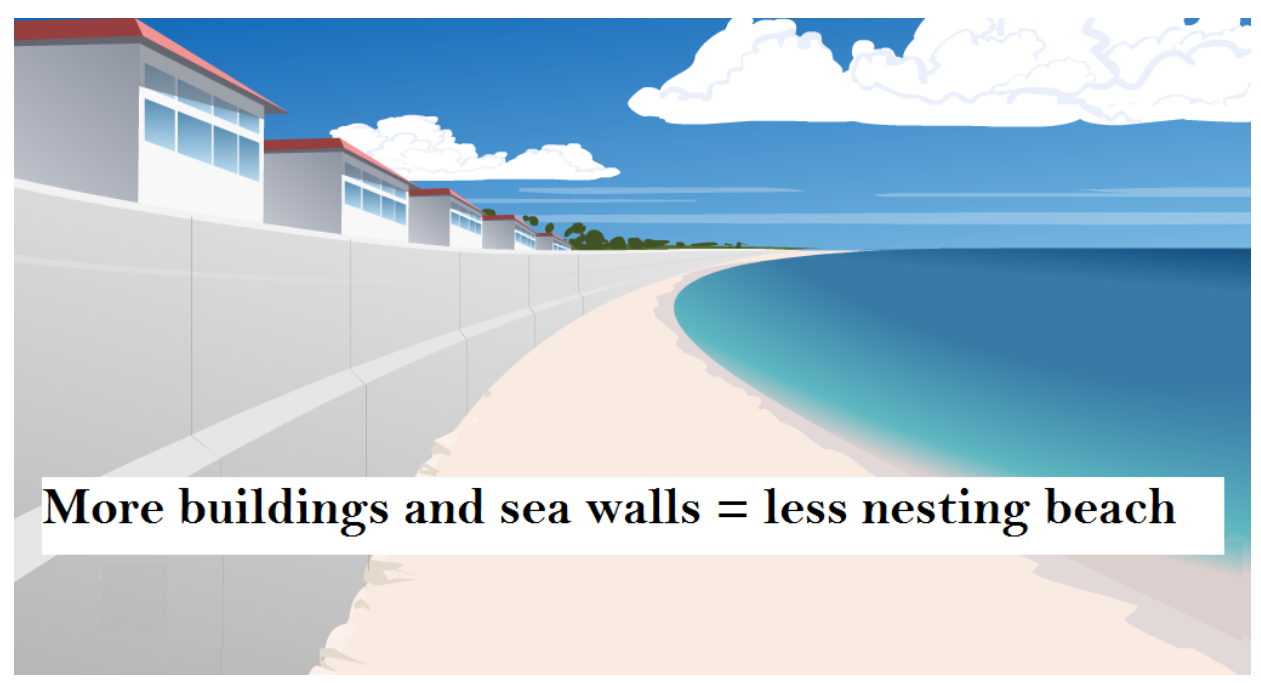

(Figure 3b: Coastal development can eradicate coastal habitat) 
Studies have shown that one promising strategy to protect sea turtle habitat is by identifying and legally protecting it. This can be done through implementation of a Coastal Construction Control Line or CCCL. A Coastal Construction Control Line will prohibit construction within a certain distance of the sea. This allows for a buffer zone between the mean sea level increase and the development which will protect sea turtle habitat of Florida coasts.

Suppose Florida policymakers were considering a proposal to extend the length of the CCCL by 100 feet in order to secure sea turtle nesting habitat. Such changes could lead the government to impose a state wide tax increase to contribute to the Ecosystem Management and Restoration Trust Fund. Suppose this proposal was put to a referendum vote.

1) Would you vote in favor of this proposal if it will cost each Florida household $\$ 25$ per year for five (5) years?
a. Yes
(skip question 3)
b. No
(skip question 2)
c. Don't know, it depends
(skip question 2)

2) Would you vote in favor of this proposal if it costs each Florida household $\$ 45$ per year for five (5) years?
a. Yes
b. No
c. Don't know, it depends

3) Would you vote in favor of this proposal if it costs each Florida household $\$ 15$ per year for five (5) years?
a. Yes
b. No
c. Don't know, it depends

4) What is the maximum amount you are willing to pay to secure sea turtle nesting habitat ? /year

5) If you were voting on this referendum today, how sure are you that you would vote the same way you answered above?

\begin{tabular}{|c|c|c|c|c|c|c|c|c|c|c|c|}
\hline $\begin{array}{c}\text { Absolutely } \\
\text { Sure }\end{array}$ & 10 & 9 & 8 & 7 & 6 & 5 & 4 & 3 & 2 & 1 & $\begin{array}{c}\text { Not } \\
\text { Sure }\end{array}$ \\
\hline
\end{tabular}


Question 6:

Compare alternative $\mathrm{A}, \mathrm{B}$, and $\mathrm{C}$ in the table below and select the option you most prefer.

Remember: Any money you spend on these alternatives is money that could have been spent on other things.

\begin{tabular}{|c|c|c|c|}
\hline Alternative Attribute & Alternative A & Alternative $B$ & Alternative $\mathrm{C}$ \\
\hline CCCL (feet) & 50 & 150 & 200 \\
\hline $\begin{array}{c}\text { Beach Nourishment } \\
\text { (Rate) }\end{array}$ & Rare & Once per 7 years & Once per 2 years \\
\hline $\begin{array}{l}\text { Green Turtle } \\
\text { ESA Status* }\end{array}$ & Endangered & Threatened & Recovered \\
\hline $\begin{array}{l}\text { Cost per year } \\
\text { Added cost to your } \\
\text { household each year for } 10 \\
\text { years }\end{array}$ & $\$ 0$ & $\$ 25$ & $\$ 60$ \\
\hline Check one box & & & \\
\hline
\end{tabular}

*Expected result in 50 years for each option

Note: Endangered $<$ Threatened $<$ Recovered 


\section{Question 7:}

Please read the statements below and check the box which best fits your views.

\begin{tabular}{|l|l|l|l|}
\hline I am aware about the effects of sea level rise on sea turtles. & & & \\
\hline Sea turtle nesting habitat on Florida's coast should be protected. & & & \\
\hline The health of the sea turtle population will affect the ecosystem. & & & \\
\hline I enjoy seeing/would enjoy seeing a sea turtle. & & & \\
\hline The health of sea turtle population will indirectly affect my life. & & & \\
\hline Sea turtle population will affect tourism in coastal cities & & & \\
\hline Limiting coastal development is a good step to conserve sea turtle habitat. & & & \\
\hline Money collected for sea turtle conservation measures will be honestly and & & & \\
\hline
\end{tabular}


Respondent Characteristics

1) Age of respondent
a. $18-30$
b. $30-45$
c. $45-60$
d. $60+$

2) Gender

a. Male

b. Female

3) Educational Background
a. Less than High school
b. High School
c. Some College
d. 4-yr college (or above)

4) Household Income
a. Below $\$ 20,000$
b. $\$ 20,000-40,000$
c. $\$ 40,000-80,000$
d. Above $\$ 80,000$

5) Number of years in Florida.
a. Less than 1 year
b. 1-5 yrs
c. 5-10 yrs
d. More than 10 years 